\title{
BMJ Open Association between HTR2C gene variants and suicidal behaviour: a protocol for the systematic review and meta-analysis of genetic studies
}

\author{
González-Castro Thelma Beatriz, ${ }^{1}$ Juárez-Rojop Isela, ${ }^{1}$ Genis Alma, ${ }^{2}$ \\ López-Narváez María Lilia, ${ }^{3}$ Tovilla-Zárate Carlos Alfonso ${ }^{4}$
}

To cite: Thelma Beatriz G-C, Isela J-R, Alma G, et al. Association between HTR2C gene variants and suicidal behaviour: a protocol for the systematic review and metaanalysis of genetic studies. BMJ Open 2014;4: $\mathrm{e} 005423$. doi:10.1136/bmjopen-2014005423

- Prepublication history for this paper is available online. To view these files please visit the journal online (http://dx.doi.org/10.1136/ bmjopen-2014-005423)

Received 8 April 2014

Revised 19 August 2014

Accepted 20 August 2014

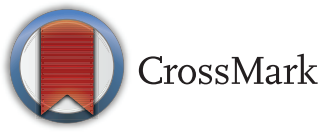

For numbered affiliations see end of article.

Correspondence to Dr Tovilla-Zárate Carlos Alfonso; alfonso_tovillaz@ yahoo.com.mx

\section{ABSTRACT}

Introduction: Suicide is an important public health problem and one of the most common causes of death throughout the world. Suicidal behaviour is complex, and its causes are multifactorial. Case-control studies have reported an association between an alteration of the serotonin system and suicidal behaviour. Recently, it has been suggested that the 5 -HTRC2 serotonin receptor gene is involved in the pathogenesis of suicidal behaviour.

Methods and analysis: To evaluate the role of the 5-HTR2C gene in suicidal behaviour, we will perform a systematic review and a meta-analysis of worldwide reports that have investigated the association between the serotonin system and suicidal behaviour. This analysis will be reported following the Preferred Reporting Items for Systematic Reviews and MetaAnalyses (PRISMA) criteria. Studies deemed fit for inclusion in the systematic review will be scored for methodological quality using the Newcastle-Ottawa Assessment Scale (NOS). The inclusion criteria will be to present independent data, to be case-control studies and to be published in journal peer reviews. To generate more accurate analyses, we will grade the reports using the GRADES scale procedures.

Ethics and dissemination: This study will describe the association between the HTR2C gene and suicidal behaviour. The results will be reported in a peerreviewed publication and in scientific presentations in Mexico and throughout the world.

Trial registration number: PROSPERO CRD42014009213.

\section{INTRODUCTION}

Suicide is the act of taking one's own life voluntarily and intentionally. Suicidal behaviour (SB) includes a wide spectrum of selfdestructive actions that can be classified as: (1) suicidal ideation (thoughts of ending one's own life, including planning a specific method to succeed), (2) attempted suicide or parasuicide (when an individual deliberately

\section{Strengths and limitations of this study}

The results could improve the understanding of the genetic component of suicidal behaviour.

- This study could show evidence of an association between the 5-HTR2C gene and suicidal behaviour

- We will perform an analysis by gender that could determine if the 5-HTR2C gene affects females and males differently.

- A small number of reports (and therefore a small sample size) is a possible limitation.

- High heterogeneity among the reports could be a limitation.

hurts himself but the act does not result in death) and (3) completed suicide (when the action ends the life of the person who carries it out). ${ }^{1-3}$ Suicide is a worldwide problem, and its prevalence has been increasing over time. ${ }^{4-6}$ Social factors alone cannot fully explain SB. ${ }^{7-9}$ Furthermore, some studies have found that there is a potential genetic component linked to SB. ${ }^{110}$

Genetic studies that have tried to identify genes that predispose certain individuals to SB have focused on genes that codify the proteins involved in the serotoninergic system because this system interferes with the control of mood, emotions, aggression and anxiety, all of which could influence SB. ${ }^{11-13}$ Recently, it has been proposed that the 5-HTR2C gene is related to $\mathrm{SB}^{10}{ }^{14-17}$ due to its association with other mental diseases such as schizophrenia, ${ }^{18-20}$ bipolar disorder, ${ }^{21}{ }^{22}$ alcoholism $^{23}$ and substance abuse. ${ }^{24}$ Furthermore, the 5-HTR2C gene has been associated with anxiety, mood disorders and impulsiveness, and these are important suicide risk factors. ${ }^{16} 25$

HTR2C (the 5-HTR2C gene) is a serotonin $2 \mathrm{C}$ receptor that lies on the $\mathrm{X}$ chromosome 
on the long arm at position Xq24-q28. HTR2C has five introns and six exons, and so far it is the only G-protein binding receptor known to undergo alternative splicing of the mRNA, resulting in more protein isoforms. ${ }^{26}$ HTR2C has a vast number of single nucleotide polymorphisms (SNPs). More than 1000 polymorphisms have been identified along the gene (according to snpper.chip.org, 2 October 2013). ${ }^{27}$ To date, the association between HTR2C and SB remains controversial because the reports include both positive and negative findings. ${ }^{28-32}$ Figure 1 shows the distribution of HTR2C and suicide studies over time. Consequently, it is important to perform a deeper study assessing the possible connection between the 5-HTR2C gene and SB.

\section{AIMS AND OBJECTIVES}

This study aims to systematically review and perform a meta-analysis on the worldwide reports that have investigated an association between the serotonin $2 \mathrm{C}$ receptor gene (5-HTR2C) and SB. In particular, it aims to focus on rs547536, rs2192372, rs4272555, rs24287207 and rs6318 polymorphisms to detect which of them act as possible risk factors.

\section{METHODS AND ANALYSIS}

\section{Systematic review and meta-analysis}

This meta-analysis will be reported following the Preferred Reporting Items for Systematic Reviews and Meta-Analyses (PRISMA) criteria. ${ }^{33}$

\section{Identification and selection of publications}

For both the systematic review and the meta-analysis, the literature will be searched from three databasesPubMed, Web of Science and EBSCO_-using the following keywords: "HTR2C and suicidal behaviour" and "HTR2C and suicide". These words will be combined to retrieve the summaries.
The selected publications will meet the following criteria: (1) to be published in peer-reviewed journals, (2) to contain independent data, (3) to be case-control association studies in which the frequencies of the three genotypes are clearly stated or could be calculated, (4) to use healthy individuals or psychiatric patients without SB as controls, (5) to include one or more of the three forms of SB (suicidal ideation, attempted suicide or completed suicide) and (6) to be written in English. The planned procedure is illustrated in figure 2 .

To determine inclusion, two researchers (G-CTB and $\mathrm{J}$-RI) will work independently to screen each of the titles, abstracts and full texts. When the researchers disagree, a third researcher (T-ZCA) will be consulted.

\section{Data extraction}

For the systematic review, the following data will be searched and analysed: authors, year of publication, region, sample size, number of cases and controls, gender, age, psychiatric diagnosis, ethnical origin and, finally, genotype and allele frequencies. The SNPs in the study will be rs547536, rs2192372, rs4272555, rs24287207 and rs6318.

The meta-analysis will be constructed following four categories: (A) exposed sick, (B) exposed not-sick, (C) not-exposed sick and (D) not-exposed not-sick. The term 'sick' refers to participants exhibiting SB and the term 'exposed' refers to the allele of risk.

The data extraction will be performed by G-CTB, J-RI, Genis-Mendoza and L-NML.

\section{Data analysis}

The systematic review will be presented in tables comparing quality measurements and the data previously mentioned. Studies deemed for inclusion will be scored for methodological quality using the Newcastle-Ottawa Assessment Scale (NOS) ${ }^{34}$ A score of six will be considered the cut-off point to distinguish higher quality

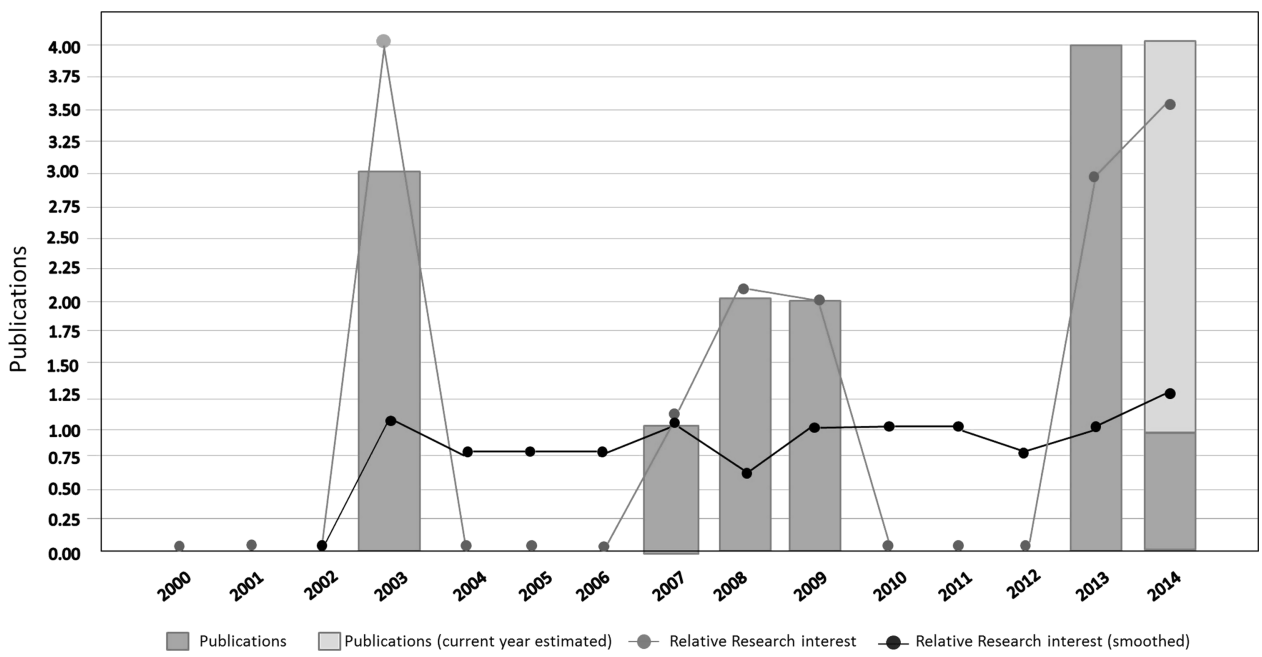

Figure 1 Distribution of association studies on the 5-HTR2C gene and suicidal behaviour published in PubMed by year (figure adapted from the results of GoPubMed). 
Figure 2 Flow chart for the search strategy and the inclusion/ exclusion criteria used in the meta-analysis and systematic review.

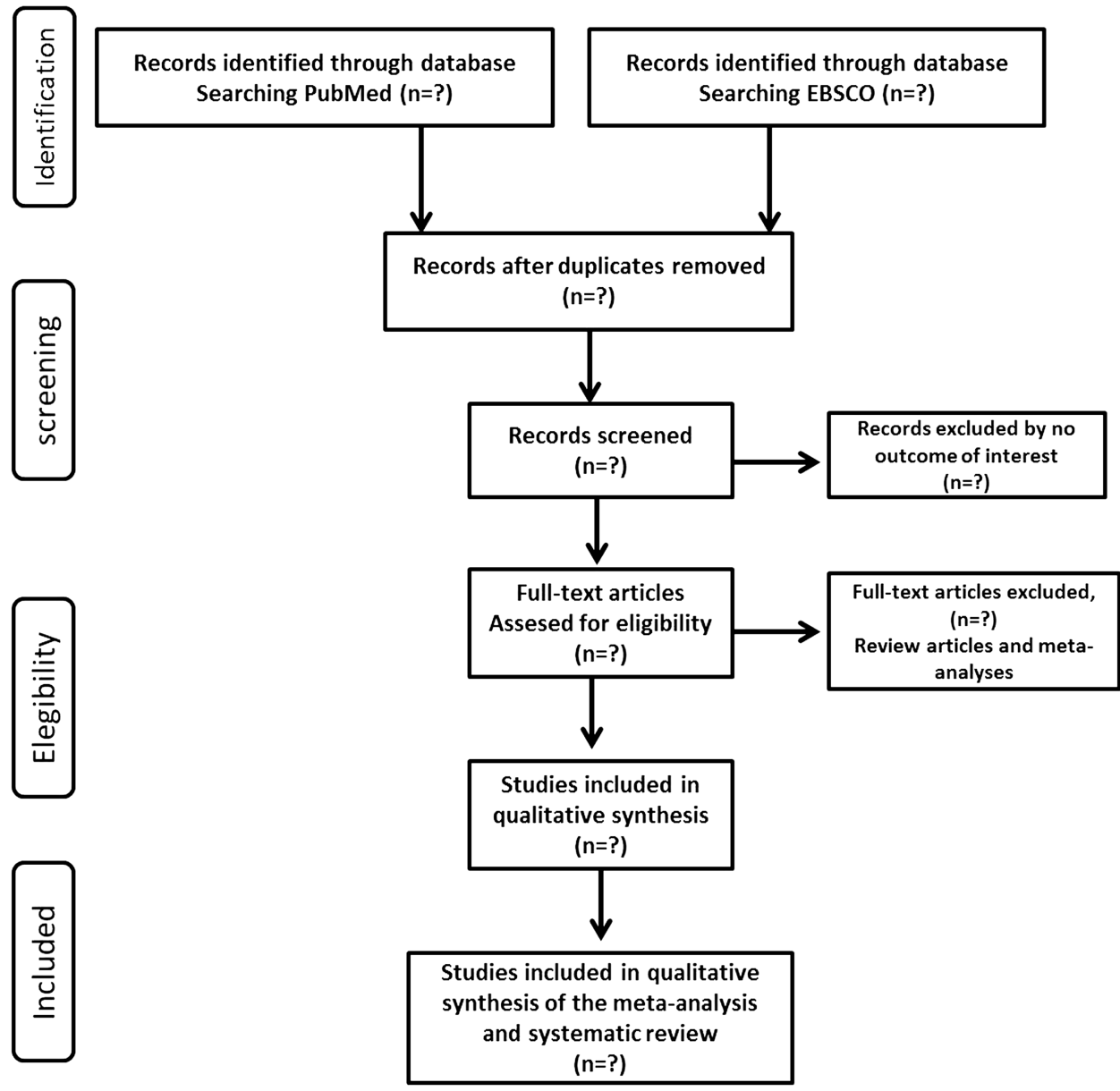

studies from lower quality studies. To give more support to our analysis, we will consider the GRADES scale procedures (http:/ /www.gradeworkinggroup.org).

For the meta-analysis, we will use the EPIDAT 3.1 program (Software for Epidemiologic Analysis of Tabulated Data, V.3.1., Pan American Health Organization; http://dxsp.sergas.es); this software is freely available for the epidemiological analysis of tabulated data. Data will be analysed using the random-effects model following the reports in the literature.$^{35-37}$ The sample heterogeneity will be measured using Dersimonian and Laird's Q test; we will also use graphs to help visualise those studies favouring heterogeneity. The results of the meta-analysis will be expressed as ORs. Pooled ORs will be calculated for each model used: viz.: allelic (example: A vs. $\mathrm{C}$ ), additive (AA vs. $\mathrm{CC}$ ), dominant (AA+AC vs. CC) and recessive (AA vs. AC+CC). Since the HTR2C is located on the $\mathrm{X}$ chromosome, an analysis by gender will be performed. To address publication bias, Egger's test and funnel plots will be calculated with the EPIDAT 3.1 software. This plotting will standardise the effect of each study on the vertical axis and its correspondent precision on the horizontal axis. Sensibility analysis will be performed. The influence of each study on global estimation will be analysed and graphed. The direction of the effect will be analysed. To evaluate genotype distribution and calculate the Hardy-Weinberg equilibrium, we will use a $\chi^{2}$ analysis.
Regarding the presence of the Hardy-Weinberg equilibrium, we will use Pearson's $\chi^{2}$ test to assess goodness of fit. Finally, Haploview $4.2^{38}$ will be used to calculate the linkage disequilibrium of the markers.

The analysed of dates will be performed be G-CTB and T-ZCA. Any differences in the interpretation will be resolved by L-NML.

\section{DISCUSSION}

Suicide is a public health problem that affects entire communities and not just the suicidal person. The medical costs and lost wages associated with suicide also take their toll on the community. Therefore, it is crucial to better understand the aetiology of $\mathrm{SB}$ as well as define how large the problem is and whom it affects.

The literature suggests that there could be a genetic factor linked to suicide. Some studies have proposed a hypothetical explanation using the stress-diathesis model and have observed that people who exhibit SB are more likely to have a family history of suicide. ${ }^{16}$ Therefore, this finding suggests that a genetic component could contribute to suicidal tendencies. ${ }^{16}$ The serotonin neurotransmission system has received the most consideration as the candidate genes linked to SB because the serotonin system regulates mood, impulsiveness and anxiety, which are important suicide risk factors. 


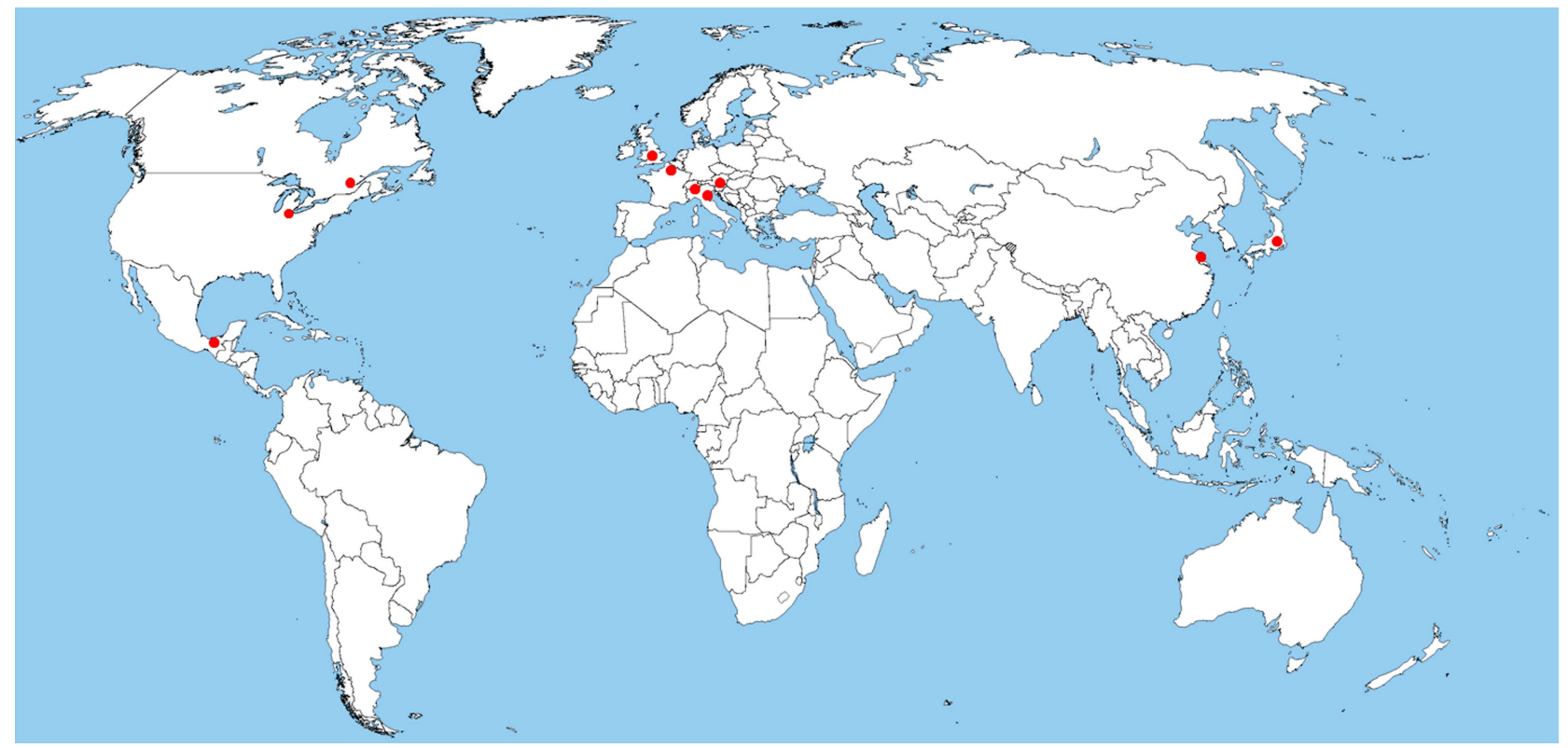

Figure 3 World map of genetic association studies of the 5-HTR2C gene with suicidal behaviour (figure adapted from the results of GoPubMed).

Furthermore, the serotoninergic function is clearly altered in suicide victims. ${ }^{10}$ Among the most studied genes are the ones that codify tryptophan hydroxylase 1 and 2 (TPH-1 and TPH-2), the serotonin transporter (5-HTT or SLC6A4) and the serotonin receptors (5-HTR1A， 5-HTR1B， 5-HTR2A， 5-HTR2C, etc.). ${ }^{39}$ Figure 3 summarises the worldwide studies linking SB with HTR2C, the gene most recently highlighted in the literature in association with SB. The 5-HTR2C gene requires a deeper analysis; therefore, by performing a systematic review and a meta-analysis, this protocol could improve the understanding of the genetic component in SB. Regarding the data analysis, we will adopt the random-effects model because it accounts for additional sources of interstudy variation when heterogeneity exists and thus has a more reliable outcome.

This meta-analysis could present some limitations. First, the association between HTR2C and SB is not widely studied; therefore, we might not find a sufficient amount of reports to analyse; furthermore, we are focusing on five polymorphisms and perhaps there are not enough reports of each one. Second, the reports will be limited to English language journals, so the number of studies might be quite small. High heterogeneity may also result due to differences in age, ethnicity, gender, education, wealth, etc. These limitations will decrease the statistical power of the study and reliability of our results.

Conversely, this will be the first meta-analysis exploring the link between the five SNPs of HTR2C and SB, specifically examining the allelic, additive, dominant and recessive models. In addition, this study protocol could demonstrate the link between the 5-HTR2C gene and SB among the general population.

Performing an analysis by gender is a strong point; in theory, owing to its chromosomal location (X chromosome), this gene must affect females and males differently. The results could help to determine if HTR2C is a risk factor in developing SB. Indirectly, our study could aid in understanding the aetiology of SB.

\section{Author affiliations}

${ }^{1}$ División Académica de Ciencias de la Salud, Universidad Juárez Autónoma de Tabasco, Villahermosa, Tabasco, México

${ }^{2}$ Servicios de Atención Psiquiátrica (SAP), Secretaría de Salud, Instituto Nacional de Medicina Genómica (INMEGEN), México, Distrito Federal, México ${ }^{3}$ Secretaria de Salud, Hospital General de Yajalón, Yajalón, Chiapas, México ${ }^{4}$ División Académica Multidisciplinaria de Comalcalco, Universidad Juárez Autónoma de Tabasco, Comalcalco, Tabasco, México

Contributors T-ZCA and G-CTB conceived the study, participated in the design and helped to draft the manuscript. GA, J-RI and L-NML helped in the selection of genes and study of polymorphisms. T-ZCA, G-CTB and GA wrote the manuscript. All of the authors read, critically revised and approved the final version of the manuscript.

Competing interests None.

Provenance and peer review Not commissioned; externally peer reviewed.

Open Access This is an Open Access article distributed in accordance with the Creative Commons Attribution Non Commercial (CC BY-NC 3.0) license, which permits others to distribute, remix, adapt, build upon this work noncommercially, and license their derivative works on different terms, provided the original work is properly cited and the use is non-commercial. See: http:// creativecommons.org/licenses/by-nc/3.0/

\section{REFERENCES}

1. Antypa N, Serretti A, Rujescu D. Serotonergic genes and suicide: a systematic review. Eur Neuropsychopharmacol 2013;23:1125-42.

2. Pooley EC, Houston K, Hawton K, et al. Deliberate self-harm is associated with allelic variation in the tryptophan hydroxylase gene (TPH A779C), but not with polymorphisms in five other serotonergic genes. Psychol Med 2003;33:775-83.

3. Serretti A, Calati R, Giegling I, et al. Serotonin receptor HTR1A and HTR2C variants and personality traits in suicide attempters and controls. J Psychiatr Res 2009;43:519-25.

4. Brzozowski FS, Soares GB, Benedet J, et al. Suicide time trends in Brazil from 1980 to 2005. Cad Saude Publica 2010;26:1293-302. 
5. Jagodic HK, Agius M, Pregelj P. Inter-regional variations in suicide rates. Psychiatr Danub 2012;24(Suppl 1):S82-5.

6. Varnik P. Suicide in the world. Int $J$ Environ Res Public Health 2012;9:760-71.

7. Bani-Fatemi A, Polsinelli G, Kennedy JL, et al. Ethnicity and suicide attempt: analysis in bipolar disorder and schizophrenia. BMC Psychiatry 2013;13:252.

8. Shinozaki G, Romanowicz M, Mrazek DA, et al. HTR2A gene-child abuse interaction and association with a history of suicide attempt among Caucasian depressed psychiatric inpatients. J Affect Disord 2013;150:1200-3.

9. Choo C, Diederich J, Song I, et al. Cluster analysis reveals risk factors for repeated suicide attempts in a multi-ethnic Asian population. Asian J Psychiatr 2014;8:38-42.

10. Sadkowski M, Dennis B, Clayden RC, et al. The role of the serotonergic system in suicidal behavior. Neuropsychiatr Dis Treat 2013;9:1699-716.

11. Tovilla-Zarate CA, Gonzalez-Castro TB, Juarez-Rojop I, et al. Study on genes of the serotonergic system and suicidal behavior: protocol for a case-control study in Mexican population. BMC Psychiatry 2014;14:29.

12. Mandelli L, Serretti A. Gene environment interaction studies in depression and suicidal behavior: an update. Neurosci Biobehav Rev 2013;37:2375-97.

13. Dracheva S, Patel N, Woo DA, et al. Increased serotonin 2C receptor mRNA editing: a possible risk factor for suicide. $\mathrm{Mol}$ Psychiatry 2008;13:1001-10.

14. Serretti A, Mandelli L, Giegling I, et al. HTR2C and HTR1A gene variants in German and Italian suicide attempters and completers. Am J Med Genet B Neuropsychiatr Genet 2007;144b:291-9.

15. Cavarec L, Vincent L, Le Borgne $C$, et al. In vitro screening for drug-induced depression and/or suicidal adverse effects: a new toxicogenomic assay based on CE-SSCP analysis of HTR2C mRNA editing in SH-SY5Y cells. Neurotox Res 2013;23:49-62.

16. Mann JJ. The serotonergic system in mood disorders and suicidal behaviour. Philos Trans R Soc Lond B Biol Sci 2013;368:20120537.

17. Iwamoto $\mathrm{K}$, Kato $\mathrm{T}$. RNA editing of serotonin $2 \mathrm{C}$ receptor in human postmortem brains of major mental disorders. Neurosci Lett 2003;346:169-72.

18. Castensson A, Aberg K, McCarthy S, et al. Serotonin receptor $2 \mathrm{C}$ (HTR2C) and schizophrenia: examination of possible medication and genetic influences on expression levels. Am J Med Genet B Neuropsychiatr Genet 2005;134b:84-9.

19. Castensson A, Emilsson L, Sundberg R, et al. Decrease of serotonin receptor $2 \mathrm{C}$ in schizophrenia brains identified by high-resolution mRNA expression analysis. Biol Psychiatry 2003;54:1212-21.

20. Thompson A, Lavedan C, Volpi S. Absence of weight gain association with the HTR2C $-759 \mathrm{C} / \mathrm{T}$ polymorphism in patients with schizophrenia treated with iloperidone. Psychiatry Res 2010;175:271-3.

21. Manchia M, Zai CC, Squassina A, et al. Mixture regression analysis on age at onset in bipolar disorder patients: investigation of the role of serotonergic genes. Eur Neuropsychopharmacol 2010;20:663-70.
22. Oruc L, Verheyen GR, Furac I, et al. Association analysis of the 5-HT2C receptor and 5-HT transporter genes in bipolar disorder. Am J Med Genet 1997;74:504-6.

23. Himei $\mathrm{A}$, Kono $\mathrm{Y}$, Yoneda $\mathrm{H}$, et al. An association study between alcoholism and the serotonergic receptor genes. Alcohol Clin Exp Res 2000;24:341-2.

24. Herman Al, Balogh KN. Polymorphisms of the serotonin transporter and receptor genes: susceptibility to substance abuse. Subst Abus Rehabil 2012;3:49-57.

25. Bortolato M, Pivac N, Muck Seler D, et al. The role of the serotonergic system at the interface of aggression and suicide. Neuroscience 2013;236:160-85.

26. De Luca V, Tharmaligam S, Strauss J, et al. 5-HT2C receptor and MAO-A interaction analysis: no association with suicidal behaviour in bipolar patients. Eur Arch Psychiatry Clin Neurosci 2008;258:428-33.

27. Riva A, Kohane IS. A SNP-centric database for the investigation of the human genome. BMC Bioinformatics 2004;5:33

28. Judy JT, Seifuddin F, Mahon PB, et al. Association study of serotonin pathway genes in attempted suicide. Am J Med Genet B Neuropsychiatr Genet 2012;1:112-19.

29. Videtic A, Peternelj TT, Zupanc T, et al. Promoter and functional polymorphisms of HTR2C and suicide victims. Genes Brain Behav 2009;8:541-5

30. Zhang J, Shen Y, He G, et al. Lack of association between three serotonin genes and suicidal behavior in Chinese psychiatric patients. Prog Neuropsychopharmacol Biol Psychiatry 2008;32:467-71.

31. Turecki G, Sequeira A, Gingras Y, et al. Suicide and serotonin: study of variation at seven serotonin receptor genes in suicide completers. Am J Med Genet B Neuropsychiatr Genet 2003;1:36-40.

32. Stefulj J, Buttner A, Kubat M, et al. 5HT-2C receptor polymorphism in suicide victims. Association studies in German and Slavic populations. Eur Arch Psychiatry Clin Neurosci 2004;254:224-7.

33. Swartz MK. The PRISMA statement: a guideline for systematic reviews and meta-analyses. J Pediatr Health Care 2011;25:1-2.

34. Stang A. Critical evaluation of the Newcastle-Ottawa scale for the assessment of the quality of nonrandomized studies in meta-analyses. Eur J Epidemiol 2010;25:603-5.

35. Gonzalez-Castro TB, Tovilla-Zarate C, Juarez-Rojop I, et al Association of the 5HTR2A gene with suicidal behavior: case-contro study and updated meta-analysis. BMC Psychiatry 2013;13:13-25.

36. Gonzalez-Castro TB, Tovilla-Zarate CA. Meta-analysis: a tool for clinical and experimental research in psychiatry. Nord $J$ Psychiatry 2013;17:17.

37. Gonzalez-Castro TB, Tovilla-Zarate CA, Juarez-Rojop I, et al. Association of 5 HTR1A gene variants with suicidal behavior: case-control study and updated meta-analysis. J Psychiatr Res 2013;47:1665-72.

38. Barrett JC, Fry B, Maller J, et al. Haploview: analysis and visualization of LD and haplotype maps. Bioinformatics 2005;21:263-5.

39. Pandey GN. Biological basis of suicide and suicidal behavior. Bipolar Disord 2013;15:524-41. 